\title{
A IMIGRAÇÃO COMO MEIO DE ATRAÇÃO DE INVESTIMENTOS DIRETOS POR PESSOA FÍSICA: ANÁLISE COMPARADA ENTRE AS POLÍTICAS BRASILEIRA, NORTE-AMERICANA E PORTUGUESA
}

\section{IMMIGRATION AS A WAY TO ATTRACT FOREIGN DIRECT INVESTMENT BY ENTREPRENEURS: A COMPARED STUDYOF POLICIES ADOPTED BY BRAZIL, UNITED STATES AND PORTUGAL}

${ }^{1}$ Florisbal de Souza Del Olmo

\section{RESUMO}

Em meio ao contexto atual de forte resistência a movimentos migratórios, especialmente em países desenvolvidos, ganha destaque o crescente fenômeno de promoção da imigração como meio de atração de investimentos externos diretos por pessoas físicas.Este trabalho discorre sobre iniciativas de atração de empreendedores estrangeiros pelo oferecimento de facilidades migratórias e tece breve análise comparativa entre as políticas aplicadaspelo Brasil, os Estados Unidos e Portugal para a atração de investidores pessoa física. Por meio de indicadores relativos à participação de imigrantes chineses como base de comparação da atratividade e dos resultados das respectivas políticas, conclui-se que os resultados mais modestos alcançados pela política brasileira decorrem, em grande parte, da sua ênfase na atração de pequenos empreendedores. Palavras-chave: imigração; investimento

Palavras-chave: Imigração, Investimento estrangeiro, Política migratória

\section{ABSTRACT}

In midst of the current anti-immigrant fervor, especially in developed countries, there is a growing trend to foster immigration as way to attract foreign direct investment by entrepreneurs who make personal investments in commercial enterprises or acquire realestate. This article examines initiatives aimed at attracting foreign entrepreneurs by offering permanent residency and makes a brief comparison between such schemes adopted by Brazil, the United States and Portugal. Given that Chinese account for a large part of the visa applications in these initiatives, data related to Chinese applications are used to assess and compare there sultsand the attractiveness of each scheme. This article concludes that the modest results obtained by the Brazilian policy are, in part, due to its emphasis in attracting small investors.

Keywords: Immigration, Foreign investment, Immigration policies

\footnotetext{
${ }^{1}$ Pós-Doutor na Universidade Federal de Santa Catarina, UFSC, Santa Catarina, SC, Brasil. Coordenador Executivo do Mestrado em Direito na Universidade Regional Integrada do Alto Uruguai e das Missões, URI, Rio Grande do Sul, RS. E-mail: florisbaldelolmo@gmail.com.
} 


\title{
INTRODUÇÃO
}

Acontecimentos recentes, como o acirramento dos conflitos no Oriente Médio e as crises sociais e econômicas decorrentes da instabilidade política no Norte do continente africano, têm impelido grande contingente populacional a procurar oportunidades fora de seu território nacional.

As tensões geradas por esse cenário de busca de redistribuição da população no espaço permitem observar que, de modo geral, raramente novos fluxos migratórios contam com apoio popular nos países receptores de imigrantes, mesmo quando tais movimentos migratórios são necessários e economicamente justifiváveis. ${ }^{1}$

Por outro lado, pode-se observar crescente interesse, especialmente por países desenvolvidos, em recepcionar potenciais empreendedores estrangeiros, dispostos a aplicar parte de seu capital em investimentos capazes de gerar emprego e renda.

As novas modalidades de mobilidade do capital e da população em diferentes partes do mundo, decorrentes de mudanças advindas de avanços tecnológicos e do processo de reestruturação produtiva, implicam em maior facilidade para o deslocamento de pessoas e de capital, com ânimo permanente ou temporário, em direção a países que proporcionem perspectivas mais vantajosas.

Conforme apontado por Neide Lopes Patarra:

\begin{abstract}
No cenário da globalização, as recentes tendências de movimentos migratórios internacionais também vêm demandando a reavaliação de paradigmas para serem melhor conhecidas e entendidas. Para tanto, tornamse imprescindíveis a incorporação de novas dimensões explicativas e uma revisão da própria definição do fenômeno migratório. ${ }^{2}$
\end{abstract}

No atual contexto de aprofundamento da globalização dos fluxos comerciais e financeiros, o Investimento Estrangeiro Direto (IED) - a participação mediante a titularidade de ações ou quotas representativas do capital social de empresas locais, detidas por investidor (pessoa física ou jurídica) não residente, domiciliado ou com sede no exterior - constitui não só um importante vetor de atração de divisas, mas também de promoção de desenvolvimento local e de geração de empregos.

\footnotetext{
1 BURUMA, Ian. Needed but not wanted. 13/12/2010. Disponível em: <https://projectsyndicate.org/commentary/needed-but-not-wanted>. Acesso em: 02/08/2015.

${ }_{2}^{2}$ PATARRA, Neide Lopes. Migrações internacionais de e para o Brasil contemporâneo: volumes, fluxos, significados e políticas. São Paulo Perspec., São Paulo, v. 19, n. 3, p. 23-33, Sept. 2005 . Disponível em: < http://dx.doi.org/10.1590/S0102-88392005000300002 >. Acesso em: 21/08/2015.
} 
Notadamente, nos últimos anos, diversos países têm elaborado programas especialmente voltados para a atração de investidores estrangeiros pessoa física. Entre outras políticas adotadas, destaca-se a concessão de facilidades migratórias, incluindo a possibilidade de residência permanente para o imigrante estrangeiro que atender determinados critérios, como montante mínimo a ser investido e a geração de empregos.

Deve-se ter presente que, via de regra, não se trata da aquisição de cidadania do país recipiendário do investimento, mas de permissão de residência permanente para o estrangeiro e seus dependentes diretos. Naturalmente, ao direito de residir somam-se as liberdades de acesso a serviços públicos, como hospitais e escolas, bem como a possibilidade de trabalhar em situação regular.

De modo geral, políticas de fomento à imigração como meio de captação de capital externo buscam atrair investidores qualificados, capazes de aportar montantes relativamente elevados. Nos Estados Unidos, por exemplo, o programa de permissão de residência permanente para empreendedores estrangeiros, conhecido como "EB-5", requer investimento pessoal mínimo de um milhão de dólares. O valor exigido pode ser reduzido a US\$ 500 mil, dependendo da área destinada. ${ }^{3}$

$\mathrm{Na}$ Europa, Portugal e Espanha adotam programas similares entre si, os quais estipulam investimentos mínimos entre 500 mil e um milhão de euros. ${ }^{4}$ Outros países requerem inversões ainda mais volumosas, como a Austrália, cuja legislação determina que o estrangeiro interessado deva investir, no mínimo, o equivalente a cerca de US\$3.650.000,00. ${ }^{5}$ Para ser elegível à obtenção de permissão de residência na China como investidor, o empreendedor estrangeiro deverá aplicar, e manter por ao menos três anos, valor entre US\$ 500 mil (em regiões mais pobres) e US\$ 2 milhões. ${ }^{6}$

O Brasil, por sua vez, adotou política significativamente menos restritiva para essa área. Nesse sentido, o Ministério do Trabalho e Emprego (MTE), por meio do Conselho Nacional de Imigração (CNIg), estipulou requisito de investimento, em moeda estrangeira, em

\footnotetext{
${ }^{3}$ U.S. CITIZEN AND IMMIGRATION SERVICES. Green Card Through Investment. Disponível em: < http://www.uscis.gov/green-card/green-card-through-job/green-card-through-investment >. Acesso em: 10/08/2015.

${ }^{4}$ PORTUGAL. Serviço de Estrangeiros e Fronteiras. Autorização de Residência para Investimento. Disponível em: <http://www.sef.pt/documentos/56/ARI_PT_jun15.pdf>. Acesso em: 05/08/2015. ${ }^{5}$ AUSTRALIA. Significant and Premium Investor Visa Programmes. Disponível em: < http://www.austrade.gov.au/invest/significant-investor-visa-and-premium-investor-visa-programmes >. Acesso em: 10/08/2015.

${ }^{6}$ SHANGHAI MUNICIPAL GOVERNMENT. Permanent Residence Certificate for Investor. Disponível em: < http://www.shanghai.gov.cn/shanghai/node17256/node17851/node17873/userobject22ai25211.html >. Acesso em: $11 / 08 / 2015$.
} 
montante igual ou superior a $\mathrm{R} \$ 150$ mil, para a obtenção de autorização para concessão de visto de residência permanente a investidores estrangeiros pessoa física. ${ }^{7}$

Tendo em vista que cidadãos chineses constituem parte significativa dos participantes de diversos dos principais programas de atração de investidores pessoas físicas, ${ }^{8}$ este estudo utilizará dados relativos a esse grupo como base de comparação da atratividade e dos resultados das políticas brasileira, norte-americana e portuguesa para investidores estrangeiros pessoa física.

\section{A POLÍTICA DOS ESTADOS UNIDOS}

Estabelecido pelo Congresso norte-americano no início da década de 1990, o programa de atração de investidores estrangeiros, conhecido como "EB-5", tem como objetivo beneficiar a economia do país por meio da geração de empregos e do investimento de capital estrangeiro. ${ }^{9}$

O programa contempla cota anual de cerca de dez mil "greencards" (vistos de residência), que podem ser concedidos a empreendedores estrangeiros que tenham realizado investimento igual ou superior a US\$ 1.000.000,00 (um milhão de dólares americanos). O valor do investimento mínimo pode ser reduzido a US\$ 500 mil se for destinado a áreas com altas taxas de desemprego ou em regiões rurais.

O processo de análise do requerimento de visto leva, em média, cerca de 26 meses para ser concluído. A título de reunião familiar, o estrangeiro contemplado poderá ter sua permissão de residência estendida ao seu cônjuge e aos seus filhos solteiros menores de 21 anos, deduzindo-se da cota de "greencards" disponíveis. Cabe ressaltar que, de acordo com a regulamentação, nenhuma nacionalidade poderá ser contemplada com mais de $7 \%$ dos vistos concedidos em cada ano.

Os detentores de visto EB-5 estão autorizados a ingressar e residir livremente nos Estados Unidos, além de poderem trabalhar e acessar a rede pública de serviços. Apesar de ser

\footnotetext{
${ }^{7}$ BRASIL. Ministério do Trabalho e Emprego. RESOLUÇÃO NORMATIVA $N^{o} .84$, DE 10 FEVEREIRO DE 2009. Disponível em: <http://www.brasilglobalnet.gov.br/ARQUIVOS/Outros/RN84p.pdf>. Acesso em: 05/08/2015.

${ }^{8}$ Chineses representam a maior parte dos aplicantes nos programas norte-americano, português, australiano, e no encerrado programa canadense.

${ }^{9}$ THE NEW YORK TIMES. A Door Into U.S. for Chinese Investors Closes - for Now. 27/08/2014. Disponível em: <http://sinosphere.blogs.nytimes.com/2014/08/27/a-door-into-u-s-for-chineseinvestors-closes-for-now/>. Acesso em: 06/08/2015.
} 
visto, em teoria, como um programa benéfico tanto para eventuais investidores estrangeiros quanto para os Estados Unidos, por vários anos as cotas não foram preenchidas. No ano de 2003, por exemplo, apenas 65 vistos EB-5 foram concedidos pelo governo norte-americano. Nos últimos cinco anos, no entanto, a popularidade do programa apresenta notável crescimento.

Em 2010, foram concedidos 1.885 vistos. No ano seguinte, a maior demanda resultou na superação da marca de um bilhão de dólares em investimentos atraídos no ano. Em 2013, 8.564 investidores foram contemplados com a permissão de residência permanente, em crescimento de $354 \%$ em relação a 2010. Apenas no estado de Nova Iorque, foram investidos US\$ 379 milhões por meio desse programa. ${ }^{10}$

Em agosto de 2014, pela primeira vez na história do programa, a cota máxima anual de dez mil vistos foi atingida. Este ano, o limite foi alcançado ainda no primeiro semestre, no mês de maio. O recente aumento da demanda está relacionado ao crescimento da participação de investidores chineses, o que motivou o Departamento de Estado norte-americano a flexibilizar a política e permitir que vagas ociosas da cota anual de vistos fossem destinadas à China. ${ }^{11}$ Desde 2013, mais de $80 \%$ dos vistos são destinados a cidadãos chineses, com investimentos superiores a US\$ 5 bilhões. ${ }^{12}$

A abundância de crédito em potencial tem atraído incorporadoras, redes hoteleiras e empresas de construção civil, em busca de alternativas menos onerosas de obtenção de financiamento, especialmente após a grave crise econômico-financeira internacional de 2008. Nesse sentido, parte significativa dos recursos disponibilizados por empreendedores estrangeiros destina-se a financiar novos empreendimentos imobiliários, como hotéis, condomínios e escritórios comerciais.

Apesar dos diversos benefícios aparentes, o programa também tem enfrentado percalços. A falta de regulamentação na aplicação e no destino dos investimentos o torna suscetível a abusos e desvios. A título ilustrativo, em 2013, descobriu-se golpe por meio do qual cerca de 300 investidores estrangeiros foram enganados, após terem desembolsado quase

\footnotetext{
${ }_{10}$ Idem. Want a Green Card? Invest in Real Estate. 17/05/2015. Disponível em: <http://www.nytimes.com/2015/05/17/realestate/want-a-green-card-invest-in-real-estate.html>. Acesso em: 06/08/2015.

${ }^{11}$ Idem, ibidem.

${ }^{12}$ Id. Chinese Account for Over 80 Percent of U.S. Investment Visa Applications. 18/03/2015. Disponível em: <http://www.nytimes.com/reuters/2015/03/18/world/asia/18reuters-china-usimmigration.html>. Acesso em: 10/08/2015.
} 
US\$ 150 milhões em projeto fictício de construção de hotel em Chicago. ${ }^{13}$ Nesses casos, além de seu dinheiro, os estrangeiros ficam sem o direito de solicitar a permissão de residência, uma vez que o investimento não se materializou.

Além dos casos de fraude, pessoas contrárias ao programa EB-5 têm levantado pontos controversos, questionando os reais benefícios da iniciativa para promover empregos nas áreas mais necessitadas, haja vista a sua concentração em regiões proeminentes - a exemplo de Nova Iorque -, bem como eventuais implicações para a segurança nacional. Uma das críticas mais contundentes sugere que esse tipo de visto consistiria, na prática, em uma forma velada de venda de acesso a direitos inerentes a cidadãos do país, o que, por sua vez, implicaria no empobrecimento do valor simbólico da nacionalidade norte-americana. Nesse sentido, um parlamentar norte-americano chegou a questionar se o país estava tão falido a ponto de precisar vender os seus direitos de cidadania ${ }^{14}$.

Por outro lado, o programa conta com o apoio explicito de grandes empresários, como Bill Gates e Warren Buffet, que defendem a ideia de que estrangeiros interessados em investir nos Estados Unidos e gerar empregos merecem ter a oportunidade de assim o fazer. ${ }^{15}$ Nesse sentido, em que pesem as diversas críticas, estima-se que o Congresso norte-americano deverá aprovar nova prorrogação da iniciativa por período de cinco anos. ${ }^{16}$

\section{A POLÍTICA PORTUGUESA}

Em 2012, como forma de estimular o setor imobiliário local e auxiliar o país a contornar a severa crise econômica, o governo português promulgou a Lei n. ${ }^{\circ}$ 29/2012, de 9 de agosto, alterando a Lei n. ${ }^{\circ}$ 23/2007, que estipula o regime jurídico de entrada, permanência, saída e afastamento de estrangeiros do território nacional. Com a alteração, definiu-se um novo regime especial de Autorização de Residência para Atividade de

\footnotetext{
${ }^{13}$ FORTUNE. The dark, disturbing world of the visa-for-sale program. 24/07/2014. Disponivel em: <http://fortune.com/2014/07/24/immigration-eb-5-visa-for-sale/>. Acesso em: 10/08/2015.

${ }^{14}$ FORTUNE. The dark, disturbing world of the visa-for-sale program. Disponível em: < http://fortune.com/2014/07/24/immigration-eb-5-visa-for-sale/ >. Acesso em: 12/08/2015.

${ }^{15}$ ANDELSON, S.; BUFFET, W.; GATES, B. Break the Immigration Impasse. in The New York Times. The Opinion Pages. 10/07/2014. Disponível em: < http://www.nytimes.com/2014/07/11/opinion/sheldon-adelson-warren-buffett-and-bill-gates-onimmigration-reform.html >. Acesso em: 12/08/2015.

${ }^{16}$ THE WALL STREET JOURNAL. Despite Critics, Lawmakers Seek Extension of Green Card Program. 28/06/2015. Disponível em: <http://www.wsj.com/articles/despite-critics-lawmakers-seekextension-1435525248>. Acesso em: 12/08/2015.
} 
Investimento (ARI) em território português, uma vez verificado o preenchimento de determinados requisitos. ${ }^{17}$

Em vigor desde outubro de 2012, o regime de ARI, também conhecido como "vistos gold”, permite que cidadãos nacionais de terceiros países possam obter autorização de residência temporária para atividade de investimento, com a dispensa de visto de residência para entrar em território português.

As pessoas contempladas com esse regime especial poderão:

a) entrar em Portugal com dispensa de visto de residência;

b) residir e trabalhar em Portugal, mesmo que temporariamente;

c) circular pelo Espaço Schengen, ${ }^{18}$ sem necessidade de obter visto; e

d) estender o regime ao seu núcleo familiar.

Apesar de ser um regime "temporário", após cinco anos é facultada a possibilidade de solicitar a concessão de Autorização de Residência Permanente, nos termos da Lei de Estrangeiros (Lei n. ${ }^{\circ}$ 23/2007), bem como de solicitar a aquisição da nacionalidade portuguesa, por naturalização, cumprindo os demais requisitos exigidos na Lei da Nacionalidade (Lei n. ${ }^{\circ}$ 37/81).

Para se tornar elegível ao regime de ARI, o investidor estrangeiro deverá atender ao menos um dos seguintes três requisitos:

1. aquisição de bens imóveis de valor igual ou superior a 500 mil euros;

2. transferência de capitais no montante igual ou superior a um milhão de euros;

3. criação de, pelo menos, 30 postos de trabalho.

De forma inovadora, os investimentos podem ser realizados tanto em caráter pessoal quanto por intermédio de uma sociedade; no entanto, considera-se imputável ao requerente de ARI apenas a proporção do investimento correspondente à sua participação no capital social. Dessa forma, dois investidores poderão formar uma sociedade e aplicar 500 mil euros cada para a aquisição de imóvel no valor de um milhão de euros.

A partir da concessão da ARI, o investidor deve manter o investimento por ao menos cinco anos. $\mathrm{O}$ regime pode ser renovado, competindo ao investidor comprovar a manutenção do investimento realizado, bem como o cumprimento da exigência de permanência mínima

\footnotetext{
${ }^{17}$ PORTUGAL, op cit.

${ }^{18} \mathrm{O}$ Espaço Schengen abrange 26 países europeus (22 dos quais são Estados-Membros da União Europeia), permitindo a livre circulação de pessoas entre os territórios dos países-membros do acordo.
} 
em território português ( 7 dias no primeiro ano e 14 dias nos subsequentes períodos de dois anos, não precisando ser contíguos).

Desde a sua implementação, o programa português tem se mostrado bem sucedido. Entre outubro de 2012 e julho de 2015, foram concedidas 2.430 Autorizações de Residência para Investimento, que resultaram na atração de investimento total no montante de 1,475 bilhão de euros. Cerca de $90 \%$ desse valor foi destinado a aquisição de imóveis. ${ }^{19}$ Ao se incluir o número de autorizações de residência a familiares, no total de 3.721 , o investimento médio per capita alcança a cifra de 240 mil euros.

Similarmente ao que ocorre nos Estados Unidos, cidadãos chineses foram contemplados com mais de $80 \%$ das autorizações concedidas pelo governo de Portugal. Brasileiros, a segunda nacionalidade em número de autorizações, representam apenas 3,5\%.

Além dos efeitos diretos na dinamização da atividade econômica, em particular no setor do imobiliário e da construção civil, bem como para a manutenção e criação de postos de trabalho, o regime especial de Autorização de Residência para Atividade de Investimento tem igualmente contribuído para o aumento da receita fiscal. Segundo dados do governo português, entre outubro de 2012 e janeiro de 2015, o regime de ARI implicou na arrecadação adicional de 100 milhões de euros de impostos. ${ }^{20}$

Estima-se que os investidores chineses sejam atraídos pela flexibilidade do programa, que requer a permanência por apenas sete dias em Portugal durante o primeiro ano. A possibilidade de circulação facilitada no Espaço Schengen configura outro grande atrativo, especialmente ao se ter em mente a exigência de obtenção prévia de visto para cidadãos chineses ingressarem de forma regular na Europa.

Apesar do significativo volume de investimentos atraído, o regime tem recebido críticas por parte de políticos portugueses, que questionam a suposta "venda da nacionalidade", bem como a "moralidade" de atrair estrangeiros endinheirados, enquanto diariamente milhares de imigrantes empobrecidos arriscam suas vidas para tentar ingressar no continente europeu. ${ }^{21}$ Apesar do apelo emocional, escapa dessas críticas o fato de tratar-se de fenômenos dissociados, cujas implicações e benefícios são geometricamente opostos.

\footnotetext{
${ }^{19}$ PORTUGAL. SEF. Autorização de Residência para Atividade de Investimento. Disponível em: <http://www.sef.pt/documentos/56/Mapa_ARI_PT_jul2015.pdf>. Acesso em: 14/08/2015.

${ }_{21}^{20}$ PORTUGAL. Disponível em: 〈http://www.portugal.gov.pt>. Acesso em: 14/08/2015.

21 THE ECONOMIST. Portugal's golden visas. 17/11/2014. Disponível em: <http://www.economist.com/blogs/charlemagne/2014/11/portugals-golden-visas>. Acesso em: $14 / 08 / 2015$.
} 


\section{A POLÍTICA BRASILEIRA}

No Brasil, compete ao Ministério do Trabalho e Emprego (MTE) a função de estabelecer as diretrizes relacionadas à autorização de trabalho a estrangeiros. O Conselho Nacional de Imigração (CNIg), por sua vez, é um órgão colegiado, criado pela Lei $\mathrm{n}^{\circ}$ 6.815/1980 (Estatuto do Estrangeiro), ${ }^{22}$ vinculado ao Ministério do Trabalho e Emprego. O CNIg tem entre suas funções: formular a política de imigração e coordenar e orientar as atividades de imigração.

Atualmente, a concessão de autorização para fins de obtenção de visto permanente para investidor estrangeiro - pessoa física - no Brasil é regida pela Resolução Normativa $n^{\circ}$ 84, de 2009, do CNIg, que revogou a Resolução Normativa n ${ }^{\circ} 60$, de 2004 . $^{23}$

Em seu artigo $1^{\circ}$, a RN 84 estipula que "O Ministério do Trabalho e Emprego poderá autorizar a concessão de visto permanente ao estrangeiro que pretenda fixar-se no Brasil com a finalidade de investir recursos próprios de origem externa em atividades produtivas." Diferentemente do programa português, portanto, a aplicação não pode visar a simples aquisição de imóvel no Brasil.

Ao se tratar de investimento que acarrete "substanciais impactos econômicos ou sociais ao País", a solicitação poderá ser encaminhada ao MTE e ao CNIg para avaliação. O único critério objetivo consiste no montante mínimo do investimento em moeda estrangeira, que deve ser em valor igual ou superior a $\mathrm{R} \$ 150.000,00$ (cento e cinquenta mil reais).

O investimento pode ser destinado a empresa nova ou já existente. Ou seja, o estrangeiro poderá se associar a uma empresa operacional, ampliando seu capital social, ou adquirir dos sócios cotas suficientes para cumprir o requisito de investimento mínimo.

A avaliação do investimento está sujeita, também, a critérios subjetivos para o deferimento do pedido de autorização de trabalho pelas autoridades imigratórias brasileiras. Conforme previsto no artigo $3^{\circ}, \S 1^{\circ}$, da $\mathrm{RN} 84$, na análise do pedido, será verificado o interesse social do investimento, conforme os seguintes critérios:

22 BRASIL. LEI $\mathrm{N}^{\mathrm{o}} 6.815$, de 19 de agosto de 1980. Disponível em: <http://www.planalto.gov.br/ccivil_03/LEIS/L6815.htm>. Acesso em: 02/08/2015.

${ }^{23}$ BRASIL. MINISTERIO DO TRABALHO E EMPREGO. CNIG. RESOLUÇÃO NORMATIVA No. 84, DE 10 FEVEREIRO DE 2009. Disponível em: <http://www.brasilglobalnet.gov.br/ARQUIVOS/Outros/RN84p.pdf>. Acesso em: 05/08/2015. 
a) quantidade de empregos gerados no Brasil, mediante a apresentação de Plano de Investimento, onde conste programa anual de geração de empregos a brasileiros;

b) valor do investimento e região do país onde será aplicado;

c) setor econômico onde ocorrerá o investimento; e

d) contribuição para o aumento de produtividade ou assimilação de tecnologia.

Tendo em vista a necessidade de obter o visto no exterior, uma vez aprovado o investimento, o Ministério do Trabalho e Emprego encaminhará Ofício ao Ministério das Relações Exteriores comunicando as autorizações, para que possa ser concedido visto permanente ao estrangeiro, que deverá apresentar requerimento em repartição consular do Brasil no exterior.

Deve-se ter presente, no entanto, que a autorização do Ministério do Trabalho e Emprego não implica na obrigatoriedade da concessão de visto permanente pelo Ministério das Relações Exteriores. De acordo com o texto da Resolução Normativa 84 do CNIg, não compete ao Ministério do Trabalho e Emprego verificar em sua análise questões como: situação migratória do estrangeiro (i.e. se o estrangeiro encontra-se em condição regular no país); antecedentes criminais (tanto no país de origem quanto no Brasil); origem dos recursos investidos; entre outros itens relevantes a serem considerados quando da concessão do visto. Ademais, cabe ressaltar que a concessão dos vistos é ato administrativo de competência exclusiva do Ministério das Relações Exteriores. ${ }^{24}$

Ao ser concedido o visto permanente, o investidor estrangeiro poderá ingressar no Brasil e obter sua Cédula de Identidade do Estrangeiro (CIE), com validade de três anos. Assim como nos outros casos estudados, a permissão de permanência no País pode ser estendida ao núcleo familiar direto do cidadão estrangeiro. De acordo com a Resolução Normativa 108 do CNIg, poderá ser concedido visto permanente, a título de reunião familiar, aos dependentes de cidadão estrangeiro permanente no Brasil. ${ }^{25}$

\footnotetext{
${ }^{24}$ BRASIL. Decreto no 86.715 , de 10 de dezembro de 1981. Disponível em: < http://www.planalto.gov.br/ccivil_03/decreto/Antigos/D86715.htm>. Acesso em: 10/08/2015. ${ }^{25}$ Idem. MINISTERIO DO TRABALHO E EMPREGO. CNIG. RESOLUÇÃO NORMATIVA Nº. 108,DE 12 DE FEVEREIRO DE 2014. Disponível em: <http://portal.mte.gov.br/data/files/8A7C816A43DF98FC014445CEE6085CD6/RESOLU\%C3\%87\% C3\%83O\%20108\%20-\%20REUNI\%C3\%83O\%20FAMILIAR.pdf>. Acesso em: 12/08/2015.
} 
Apesar de estar previsto que o Conselho Nacional de Imigração poderá alterar o valor mínimo de investimento, até a presente data ${ }^{26}$ o montante permanece o mesmo desde a entrada em vigor da RN 84 do CNIg. Cabe observar que, no período entre a publicação da Resolução Normativa, em fevereiro de 2009, e a elaboração do presente artigo, em agosto de 2015, a inflação brasileira, calculada pelo índice IGP-M, foi superior a $43 \% .^{27}$ Do ponto de vista cambial, o piso estabelecido também se mostra defasado. Quando da entrada em vigor da RN 84, o valor do investimento mínimo exigido correspondia a cerca de US\$ 66 mil. Atualmente, devido à significativa desvalorização do real frente ao dólar, o montante representa menos de US\$ 44 mil.

A abismal diferença entre os montantes exigidos pelo Brasil, em comparação a países como Estados Unidos e Portugal, torna evidente que a política nacional visa atrair microempresários estrangeiros, capazes de gerar postos de trabalho para mão de obra pouco qualificada.

Segundo relatório elaborado pela Coordenação Geral de Imigração, cerca de um terço dos estrangeiros que receberam autorização de trabalho como investidor pessoa física, entre 2011 e 2014, detinham apenas ensino médio completo. ${ }^{28}$ Nesse período, foram concedidas 4.374 autorizações, sendo a maior parte destinada a cidadãos italianos (26\%), portugueses (19\%) e chineses (15\%). São Paulo e Rio de Janeiro, em conjunto, concentraram $40 \%$ dos investidores e $35 \%$ dos investimentos. ${ }^{29}$

No total, entre 2011 e 2014, o montante atraído alcançou a cifra de um bilhão de reais. Apesar de, em primeira análise, o valor parecer considerável, em termos relativos, trata-se de pequena fração se comparado aos números obtidos pelos programas norteamericano e português, apresentados anteriormente.

Em média, cada investidor estrangeiro aplicou R\$ 230 mil no País. Para os investidores chineses, no entanto, a média observada foi mais próxima ao valor mínimo exigido para qualificar para a obtenção de visto permanente de investidor, alcançando $\mathrm{R} \$ 179$ mil. Tendo em conta a elevada taxa de poupança chinesa, superior a $50 \%^{30}$, em tese o relativamente baixo investimento necessário permitiria que um maior número em potencial de

\footnotetext{
${ }^{26} 15$ de agosto de 2015.

27 BANCO CENTRAL DO BRASIL. Calculadora do Cidadão. Disponível em: <https://www3.bcb.gov.br/CALCIDADAO>. Acesso em: 15/08/2015.

${ }^{28}$ BRASIL. MINISTÉRIO DO TRABALHO E EMPREGO. Coordenação Geral de Imigração. Autorizações concedidas a estrangeiros. Brasília, 2015.

${ }^{29}$ Idem. Ibidem.

${ }^{30}$ BANCO MUNDIAL. Disponível em: < http://data.worldbank.org/country/china >. Acesso em: 15/08//01.
} 
empreendedores chineses consiga atender os requisitos para a solicitação de visto permanente de investidor no Brasil. Não se trata, portanto, do mesmo tipo de investidor que se candidata ao greencard norte-americano ou ao visto gold português. No entanto, a baixa adesão evidencia pouco interesse ou desconhecimento a respeito do programa brasileiro.

Apesar de o estudo da CGI não divulgar o número de dependentes que acompanham cada investidor, a título apenas ilustrativo, tomando como base a média observada no regime português, de 1,5 dependente por investidor, poder-se-ia estimar que, de modo geral, o investidor chinês desembolse cerca de 72 mil reais por visto permanente brasileiro. Com a ressalva de ser apenas uma conjectura, é possível supor que esse valor, ao câmbio atual ${ }^{31}$, possivelmente tornaria o visto permanente brasileiro um dos mais baratos do mundo.

Os valores relativamente baixos dos investimentos realizados pelos estrangeiros contemplados com o visto permanente para investidor pessoa física permitem indagar sobre o tipo de empreendimento aos quais se destinam as inversões estrangeiras. Não por acaso, em pesquisa no Diário Oficial da União, é possível encontrar referências a autorizações de vistos permanentes para investidores estrangeiros que aplicaram seu dinheiro em estabelecimentos como pastelarias e lojas de armarinho ${ }^{32}$.

Tendo em conta a elevada concentração dos investimentos em grandes centros urbanos, o montante tipicamente aplicado, bem como os tipos possíveis de estabelecimentos comerciais aos quais se destinam os investimentos, não se pode descartar a possibilidade de que seja, na prática, pouco relevante a análise sobre a "contribuição para o aumento de produtividade ou assimilação de tecnologia”, decorrente do investimento estrangeiro, ou, até mesmo, o seu real interesse social, conforme os critérios definidos na Resolução Normativa 84.

Haja vista a rápida desvalorização cambial do real e os crescentes índices de inflação no País, em análise crítica, seria possível questionar se o valor em moeda estrangeira atraído para o Brasil seria suficiente para contrapor, em médio e longo prazo, os gastos em serviços públicos oferecidos aos estrangeiros que passarão a residir permanentemente no País.

Deve-se ter presente que, com um visto permanente, os dependentes do cidadão estrangeiro poderão frequentar escolas públicas no Brasil, bem como ter acesso ao sistema

\footnotetext{
${ }_{31}^{31}$ Em 24/08/2015, US\$ 1,00 equivale a aproximadamente R \$3,50.

${ }^{32}$ Para encontrar processos publicados no DOU, basta procurar pela expressão "Permanente - Sem Contrato - RN 84 - Resolução Normativa, de 10/02/2009:".
} 
público de saúde. Nesse sentido, o aumento da presença de nacionais chineses já tem sido observada. $^{33}$

Apesar dos pontos controversos apontados, curiosamente, ao contrário dos programas norte-americano e português, não se observam críticas contundentes, na mídia ou nos meios políticos, a respeito da iniciativa brasileira para atração de investimentos estrangeiros de pessoas físicas.

\section{CONCLUSÃO}

Diferentemente de outros tipos de fluxos migratórios, geralmente indesejados pelos países, tem crescido a oferta de programas para fomentar a imigração como meio de atração de investimentos diretos por pessoa física. Por trás de tais programas, está o potencial de dinamizar a economia local por meio do uso de capital externo que, provavelmente, não estaria disponível de outra forma.

Detentora da maior classe média do mundo, com mais de 400 milhões de pessoas, a China se destaca como um dos principais países alvo de tais políticas. Não por acaso, cidadãos chineses representam mais de $80 \%$ dos agraciados com autorizações de residência nos Estados Unidos e em Portugal, em programas de atração de investidores estrangeiros pessoa física.

O elevado valor necessário para qualificar a possibilidade de obter a permissão de residência nos referidos países parece ter como intuito, além de maximizar a captação de recursos, diferenciar esse tipo de imigrante dos que procuram escapar de condições sociais precárias em seus países de origem.

No Brasil, no entanto, os requisitos materiais significativamente mais baixos parecem ir de encontro aos objetivos das políticas adotadas em Portugal e nos Estados Unidos. Nesse sentido, as diferenças entre os programas estudados permitem constatar que a iniciativa brasileira não se apresenta como concorrente com as demais, uma vez que está direcionada a empreendedores de pequeno e micro porte.

Ao voltar-se à atração de pequenos e microempresários, o País evidencia maior ênfase na possibilidade de geração de postos de trabalho para mão de obra pouco qualificada,

\footnotetext{
${ }^{33}$ FOLHA DE SÃO PAULO. Grávidas chinesas fazem posto de saúde falar chinês em São Paulo. Disponível em: < http://www1.folha.uol.com.br/cotidiano/2015/08/1672455-gravidas-chinesas-fazem-posto-de-saude-falarchines-em-sao-paulo.shtml >. Acesso em: 24/08/2015.
} 
ao invés de promover estímulos diretos a grandes setores, como a construção civil. Esse direcionamento resulta, também, em captação significativamente menor de recursos externos, em comparação com as outras iniciativas verificadas, que chegam a apresentar resultados financeiros dezenas de vezes superiores aos do Brasil.

Em que pese seus resultados comparativamente menos expressivos, diferentemente dos outros programas estudados, a iniciativa brasileira não parece estar sujeita a críticas a respeito da "precificação da cidadania", apesar do comparativamente baixo custo de obtenção da autorização de residência permanente no País para investidores estrangeiros pessoa física.

\section{REFERÊNCIAS}

ANDELSON, S.; BUFFET, W.; GATES, B. Break the Immigration Impasse. in The New York Times. The Opinion Pages. 10/07/2014. Disponível em: < http://www.nytimes.com/2014/07/11/opinion/sheldon-adelson-warren-buffett-and-bill-gateson-immigration-reform.html >. Acesso em: 12/08/2015.

AUSTRALIA. Significant and Premium Investor Visa Programmes. Disponível em: $<\quad$ http://www.austrade.gov.au/invest/significant-investor-visa-and-premium-investor-visaprogrammes >. Acesso em: 10/08/2015.

BANCO CENTRAL DO BRASIL. Calculadora do Cidadão. Disponível em: <https://www3.bcb.gov.br/CALCIDADAO>. Acesso em: 15/08/2015.

BANCO MUNDIAL. Disponível em: < http://data.worldbank.org/country/china >. Acesso em: 15/08//01.

BRASIL. MINISTÉRIO DO TRABALHO E EMPREGO. RESOLUÇÃO NORMATIVA $N^{o}$. 84, DE 10 FEVEREIRO DE 2009. Disponível em: <http://www.brasilglobalnet.gov.br/ARQUIVOS/Outros/RN84p.pdf>. Acesso em: 05/08/2015.

LEI $\mathrm{N}^{\circ}$ 6.815, de 19 de agosto de 1980. Disponível em:

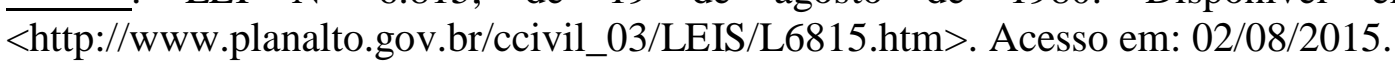

. Decreto $\mathrm{N}^{\mathrm{o}}$ 86.715, de 10 de dezembro de 1981. Disponível em: < http://www.planalto.gov.br/ccivil_03/decreto/Antigos/D86715.htm>. Acesso em: 10/08/2015.

MINISTÉRIO DO TRABALHO E EMPREGO. CNIG. RESOLUÇÃO NORMATIVA No. 84, DE 10 FEVEREIRO DE 2009. Disponível em: <http://www.brasilglobalnet.gov.br/ARQUIVOS/Outros/RN84p.pdf>. Acesso em: 05/08/2015.

MINISTÉRIO DO TRABALHO E EMPREGO. CNIG. RESOLUÇÃO NORMATIVA $\mathrm{N}^{\circ}$. 108, DE 12 DE FEVEREIRO DE 2014. Disponível em: 
<http://portal.mte.gov.br/data/files/8A7C816A43DF98FC014445CEE6085CD6/RESOLU\%C 3\%87\%C3\%830\%20108\%20-\%20REUNI\%C3\%830\%20FAMILIAR.pdf>. Acesso em: $12 / 08 / 2015$. Imigração. Autorizações concedidas a estrangeiros. Brasília, 2015.

BURUMA, Ian. Needed but not wanted. 13/12/2010. Disponível em: <https://project-syndicate.org/commentary/needed-but-not-wanted>. Acesso em: 02/08/2015.

FOLHA DE SÃO PAULO. Grávidas chinesas fazem posto de saúde falar chinês em São Paulo. Disponível em: < http://www1.folha.uol.com.br/cotidiano/2015/08/1672455- gravidaschinesas-fazem-posto-de-saude-falar-chines-em-sao-paulo.shtml >. Acesso em: 24/08/2015.

FORTUNE. The dark, disturbing world of the visa-for-sale program. 24/07/2014. Disponível em: <http://fortune.com/2014/07/24/immigration-eb-5-visa-for-sale/>. Acesso em:

10/08/2015.

PATARRA, Neide Lopes. Migrações internacionais de e para o Brasil contemporâneo: volumes, fluxos, significados e políticas. São Paulo Perspec., São Paulo , v. 19, n. 3, p. 23-33, Sept. 2005. Disponível em: < http://dx.doi.org/10.1590/S010288392005000300002 >. Acesso em: 21/08/2015.

PORTUGAL. Serviço de Estrangeiros e Fronteiras. Autorização de Residência para Investimento. Disponível em: 〈http://www.sef.pt/documentos/56/ARI_PT_jun15.pdf>. Acesso em: 05/08/2015.

. SEF. Autorização de Residência para Atividade de Investimento. Disponível em:

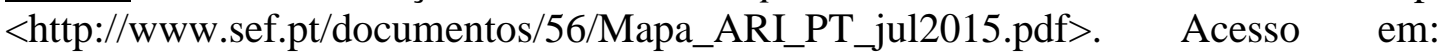
$14 / 08 / 2015$.

. Disponível em: <http://www.portugal.gov.pt>. Acesso em: 14/08/2015.

SHANGHAI MUNICIPAL GOVERNMENT. Permanent Residence Certificate for Investor. Disponível em:

http://www.shanghai.gov.cn/shanghai/node17256/node17851/node17873/userobject22ai2521

1.html >. Acesso em: 11/08/2015.

THE ECONOMIST. Portugal's golden visas. 17/11/2014. Disponível em: <http://www.economist.com/blogs/charlemagne/2014/11/portugals-golden-visas >. em: $14 / 08 / 2015$.

THE NEW YORK TIMES.A Door Into U.S. for Chinese Investors Closes - for Now.27/08/2014. Disponível em: <http://sinosphere.blogs.nytimes.com/2014/08/27/a-door- intou-s-for-chinese-investors-closes-for-now/>. Acesso em: 06/08/2015.

. Want a Green Card? Invest in Real Estate. 17/05/2015. Disponível em: <http://www.nytimes.com/2015/05/17/realestate/want-a-green-card-invest-in-realestate.html>. Acesso em: 06/08/2015. 
$18 / 03 / 2015$.

Chinese Account for Over 80 Percent of U.S. Investment Visa Applications.

<http://www.nytimes.com/reuters/2015/03/18/world/asia/18reuters-china-us-

em:

immigration.html>. Acesso em: 10/08/2015.

THE WALL STREET JOURNAL. Despite Critics, Lawmakers Seek Extension of Green Card Program. 28/06/2015. Disponível em: <http://www.wsj.com/articles/despitecritics-lawmakers-seek-extension-1435525248>. Acesso em: 12/08/2015.

U.S. CITIZEN AND IMMIGRATION SERVICES. Green Card Through Investment. Disponível em: < http://www.uscis.gov/green-card/green-card-through-job/greencard-through-investment >. Acesso em: 10/08/2015. 